\title{
Up-to-date solutions for reducing electricity consumption in lighting installations
}

\author{
Stawomir Sowa ${ }^{1, *}$ \\ ${ }^{1}$ Institute of Electric Power Engineering, Faculty of Electrical Engineering Poznan University of Technology, Poland
}

\begin{abstract}
Lighting is an important part of the building installations. Current lighting trends in the public and private sectors make lighting energy a significant part of the total electricity consumption of facilities. The provisions included in the standards, directives and regulations prescribe the implementation of the measures contributing to the reduction of electricity consumption, i.e. the improvement of energy efficiency of facilities. The article shows current trends and solutions concerning the reduction of electricity consumption in lighting installations, with the main focus on public utility facilities. The proposed systems are universal and can be implemented in various objects with different purpose and use.
\end{abstract}

\section{Introduction}

The increasing consumption of the electricity used for lighting is the result of the widespread trend to use more complex lighting systems. This applies to commercial and public buildings as well as to households. The global trend of implementing eco-friendly solutions and the need to reduce the maintenance costs of the facilities caused a great interest in solutions that introduce energy savings [1]. The introduction of innovative lighting control solutions is implemented at the stage of designing new facilities or in the situation where the modernization of the building is planned. The biggest savings in electricity consumption for lighting can be achieved in public facilities (schools, offices) and companies. While the costs of energy consumption in companies are balanced economically with their activities, in public utility buildings, the economic aspect of energy savings is often neglected. Energy used for lighting in the households accounts for $9.7 \%$ of the total cost of the electrical power [2]. In public buildings it is already twice as much, and in the case of companies and shops up to three times. The implementation of basic ways to reduce energy consumption is not a complicated process, and the investment usually pays for itself within a few years.

\subsection{How to reduce electricity consumption for lighting}

\subsubsection{New facilities}

In the new public utility objects, the architects are obliged to comply with the standards related to lighting [3]. The appropriate distribution and use of proper lighting sources ensures the required lighting intensity at the same time as low energy consumption. In addition, the implemented system of lighting control ensures high comfort of use and increases the energy efficiency of the facilities [4]. New buildings may be characterized by high energy efficiency due to the possibility of using modern lighting fixtures, which are installed in strictly defined places. The energy-saving light sources together with the sublime control system may result in significant savings. Lighting engineers should also refer to the latest research, which allows to precisely determine the places of installation of lighting fixtures and the use of appropriate automation of lighting control $[5,6]$.

\subsubsection{Existing buildings}

In the existing facilities, the introduction of energysaving solutions for lighting is difficult. The main obstacle is the considerable number of costs resulting from the need to modernize the lighting system. The most common way to increase energy efficiency in lighting systems is to replace light sources with energysaving ones. Another solution is the replacement of the entire lighting fixtures and replace the existing ones with e.g. LED fixtures. A further solution is the installation of PIR motion detectors, which are supposed to automatically switch off the lighting when the user is absent. The implementation of solutions that allow, for example, independent regulation of the rows or single luminaires, requires a major modernization of the circuits that supply the luminaires. There are already modern technologies and solutions which enable automatic control of single luminaires without the need to modernize lighting circuits. One of such solutions is presented in the next paragraph of this article. 


\subsubsection{Intelligent control}

The smart control systems are increasingly popular solutions for new facilities. High expectations of the users force the investors to use the most advanced technologies to control and manage installations in the facility. The use of PIR motion sensors, lighting intensity sensors, programmable executive and control devices allows to increase the comfort of use, improves the safety of the facility and reduces the consumption of electricity. In addition, the use of renewable energy sources combined with the intelligent control systems in the facilities may balance the energy generated from RES with the total energy demand in the building [7]. Such a situation takes place in the existing zero energy facilities.

\subsection{Energy savings}

The implementation of the right control system can lead to savings of up to $45 \%$ of total lighting energy consumption [4]. Intelligent lighting systems can save up to $68 \%$ in electricity consumption. Such lighting system is described in paragraph 2 of this article.

\section{Highly advanced lighting control systems}

There are modern lighting systems that provide a constant illumination of the surface and react to the appropriate value of daylight intensity and the presence of the user in the room. The DALI standard is quite popular in this group of modern lighting systems. It enables fluent regulation of the lighting intensity of individual luminaires. This will only be effective if it is equipped with an extensive system of motion sensors, light intensity measurement and appropriate control of individual luminaires. It requires a separate installation and assembly of additional measuring and control equipment. It is being successfully used in new facilities. There are now available lighting systems that enable smooth regulation of the light flux in individual, single luminaires and do not require changes in the existing installation. Innovation is based on the use of special luminaires, each is equipped with motion and light intensity sensors. In addition, the luminaires are wirelessly connected to other nearby luminaires, providing the information about the state of the operation. Such a solution does not require additional wiring, because only traditional power supply is needed to operate the luminaire. Currently, this is one of the most advanced lighting systems, which enables quick installation, without the need to upgrade the installation and run special software. An overview of the system's operation is shown in Figure 1.

\section{Summary}

Lighting installations consume a significant amount of electricity in the facilities. This is a result of a very complex lighting systems, which are installed in order to meet the requirements of lighting standards, as well as visualization and decorative reasons. Existing lighting control systems are based on lighting automation systems, which in combination with energy-saving luminaires, lighting sources, provides large savings in electricity consumption. The further development of the lighting systems will provide even more convenience in the use of rooms, by ensuring uniform, required lighting, and at the same time will improve the energy efficiency of facilities, reducing electricity consumption for lighting.

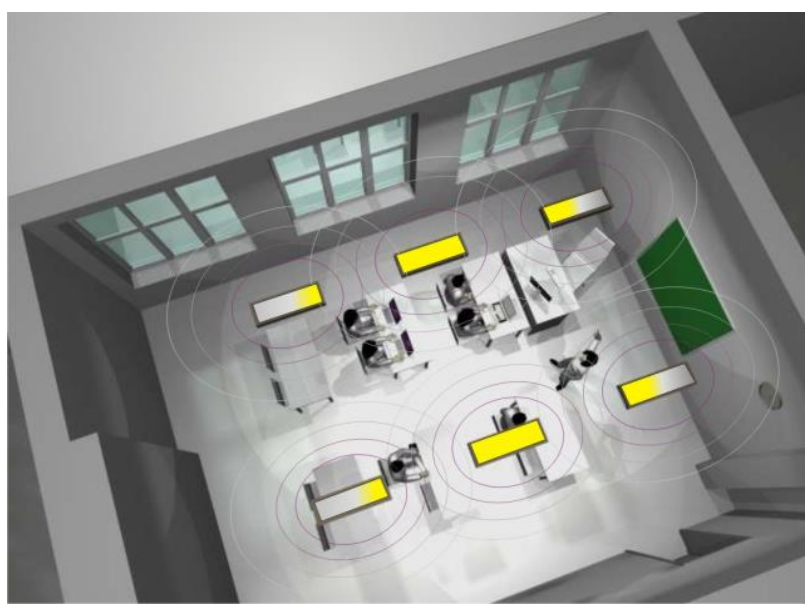

Fig. 1. General idea of the intelligent luminaire system [source: own elaboration].

\section{References}

1. Directive 2012/27/EU of the European Parliament and of the Council of 25 October 2012 on energy efficiency 2012/27/UE, Brussels (2012)

2. Efektywność wykorzystania energii w latach 2006 - 2016, Informacje i opracowania statystyczne, GUS 15,06.2018. Warszawa (2018)

3. EN:15193 Energy performance of buildings Energy requirements for lighting (2017)

4. S. Sowa, Possibile Ways to Improve the Energy efficiency of the lighting system in public facilities. Electrical Engineering 98, 137-147 (2019)

5. S. Sowa, The Intensity of daylight in school building. Informatyka Automatyka Pomiary w Gospodarce i Ochronie Środowiska 3, 78-81 (2017)

6. S. Sowa, J. Gielniak. Lighting control algorithms in a school venue using KNX system. Electrical Engineering 96, 153-162 (2018)

7. Sowa S. Increasing the energy efficiency of hybrid RES installations using KNX system. Renewable Energy Sources: Engineering, Technology, Innovation, 387-394, Springer (2018) 